Article

\title{
Anti-Inflammatory Mesenchymal Stromal Cell-Derived Extracellular Vesicles Improve Pathology in Niemann-Pick Type C Disease
}

\author{
Lien Van Hoecke ${ }^{1,2}$, Caroline Van Cauwenberghe ${ }^{1,2}$, Verena Börger $\left.{ }^{3}{ }^{(}\right)$, Arnout Bruggeman ${ }^{1,2} \mathbb{D}^{-}$, \\ Jonas Castelein ${ }^{1,2}$, Griet Van Imschoot ${ }^{1,2}$, Elien Van Wonterghem ${ }^{1,2}$, Robin Dittrich ${ }^{3}$, Wouter Claeys ${ }^{1,2,4}$, \\ Junhua Xie ${ }^{1,2}$, Bernd Giebel ${ }^{3}(\mathbb{D})$ and Roosmarijn E. Vandenbroucke ${ }^{1,2, *(\mathbb{C})}$
}

1 VIB Center for Inflammation Research, VIB, 9052 Ghent, Belgium; lien.vanhoecke@irc.vib-ugent.be (L.V.H.); caroline.vancauwenberghe@thomasmore.be (C.V.C.); Arnout.Bruggeman@irc.VIB-UGent.be (A.B.); jonas.castelein@irc.vib-ugent.be (J.C.); Griet.VanImschoot@irc.VIB-UGent.be (G.V.I.); Elien.VanWonterghem@irc.VIB-UGent.be (E.V.W.); Wouter.Claeys2@irc.vib-ugent.be (W.C.); Junhuax@irc.vib-ugent.be (J.X.)

2 Department of Biomedical Molecular Biology, Ghent University, 9000 Ghent, Belgium

3 Institute for Transfusion Medicine, University Hospital Essen, University Duisburg-Essen, 45147 Essen, Germany; verena.boerger@uk-essen.de (V.B.); robin.dittrich@uk-essen.de (R.D.); bernd.giebel@uk-essen.de (B.G.)

Citation: Van Hoecke, L.; Van Cauwenberghe, C.; Börger, V.; Bruggeman, A.; Castelein, J.; Van Imschoot, G.; Van Wonterghem, E.; Dittrich, R.; Claeys, W.; Xie, J.; et al. Anti-Inflammatory Mesenchymal Stromal Cell-Derived Extracellular Vesicles Improve Pathology in Niemann-Pick Type C Disease. Biomedicines 2021, 9, 1864. https:// doi.org/10.3390/biomedicines9121864

Academic Editors: María

Gutiérrez-Fernández and Laura Otero-Ortega

Received: 26 October 2021

Accepted: 3 December 2021

Published: 8 December 2021

Publisher's Note: MDPI stays neutral with regard to jurisdictional claims in published maps and institutional affiliations.

Copyright: (c) 2021 by the authors. Licensee MDPI, Basel, Switzerland. This article is an open access article distributed under the terms and conditions of the Creative Commons Attribution (CC BY) license (https:/ / creativecommons.org/licenses/by/ $4.0 /)$.
4 Liver Research Center Ghent, Hepatology Research Unit, Department of Internal Medicine and Pediatrics, Ghent University, 9000 Ghent, Belgium

* Correspondence: Roosmarijn.Vandenbroucke@irc.VIB-UGent.be; Tel.: +32-9-33-13730
Abstract: Niemann-Pick type C (NPC) disease is a rare neurovisceral lipid storage disease with progressive neurodegeneration, leading to premature death. The disease is caused by loss-of-function mutations either in the NPC1 or NPC2 gene which results in lipid accumulation in the late endosomes and lysosomes. The involved disease mechanisms are still incompletely understood, making the design of a rational treatment very difficult. Since the disease is characterized by peripheral inflammation and neuroinflammation and it is shown that extracellular vesicles (EVs) obtained from mesenchymal stromal cells (MSCs) provide immunomodulatory capacities, we tested the potential of MSC-EV preparations to alter NPC1 disease pathology. Here, we show that the administration of an MSC-EV preparation with in vitro and in vivo confirmed immune modulatory capabilities is able to reduce the inflammatory state of peripheral organs and different brain regions of NPC1-diseased mice almost to normal levels. Moreover, a reduction of foamy cells in different peripheral organs was observed upon MSC-EV treatment of $\mathrm{NPC1}^{-/-}$mice. Lastly, the treatment was able to decrease microgliosis and astrogliosis, typical features of NPC1 patients that lead to neurodegeneration. Altogether, our results reveal the therapeutic potential of MSC-EVs as treatment for the genetic neurovisceral lipid storage disease NPC, thereby counteracting both central and peripheral features.

Keywords: Niemann-Pick type C disease; extracellular vesicles; mesenchymal stem cell

\section{Introduction}

Niemann-Pick disease type C (NPC) is a neurovisceral disorder represented by a dominant progressive neurodegenerative involvement in $90 \%$ of the patients [1]. It is a lipid storage disease characterized by oxidative stress and impaired trafficking of unesterified cholesterol and glycosphingolipids in the late endosome and lysosome system. The clinical symptoms associated with NPC are heterogeneous and vary from patient to patient [2]. None of the symptoms on its own are specific for the disease, it is rather the combination of different manifestations that is indicative for NPC [3]. In general, two types of symptoms can be distinguished, namely systemic and neurologic symptoms. The systemic symptoms include enlargement and inflammatory damage of liver and spleen and pulmonary diseases 
caused by the presence of foamy cells. Neuropathologically the disease is characterized by ballooned neurons distended with lipid storage, widespread neuronal loss, microgliosis, and astrogliosis [4]. Furthermore, neural stem cells derived from NPC disease models have decreased ability for self-renewal and neuronal differentiation. In a cross-sectional study of NPC patients, Walterfang et al. showed that neuroinflammation, particularly in white matter, substantiate structural and degenerative changes in the brain of NPC patients [5]. In addition to being a disrupted lysosome function disorder, NPC demonstrates a significantly dysregulation of innate immunity [6].

At present, there is no cure for NPC1 patients as the exact mechanism behind the disease is insufficiently known [6]. Therefore, the treatment of NPC1 is focused on the alleviation of symptoms like management of seizures with antiepileptic drugs, tremor might be improved in some cases by anticholinergic drugs, and spasticity may also be managed by physiotherapy [7]. Nevertheless, there is an urgent need for novel therapies that address the systemic as well as the neurodegenerative symptoms more efficient. As the disease is characterized by its proinflammatory status, immune modulatory treatments appear an attractive therapeutic strategy.

Mesenchymal stromal cells (MSCs) emerged as a potential NPC therapy [8]. These cells promote anti-inflammatory immune responses and suppress pro-inflammatory responses $[9,10]$. More precisely, they promote regulatory T-cell formation, shift proinflammatory macrophage functions towards anti-inflammatory activities, and secrete antiinflammatory cytokines. Due to these immunomodulatory characteristics, MSCs represent a promising tool for cell therapy in different inflammatory disease settings. In one of the first studies, back in 2004, Le Blanc and colleagues successfully used bone marrow-derived MSCs to suppress graft-vs.-host disease (GvHD) symptoms in a severe treatment resistant grade IV acute patient [11]. Since then, MSCs were administered as immunomodulatory drug to GvHD patients and to patients suffering from other inflammatory diseases in many different studies. Amongst others, two clinical phase III studies were performed to treat steroid-refractory GvHD patients with commercial MSC products. While the first study on adult GvHD study failed to show efficacy $[12,13]$, the second study on pediatric GvHD patient showed therapeutic MSC effects [14,15].

Increasing evidence indicates that MSCs exert their therapeutic effects in a paracrine manner rather than by direct cellular interactions as it was assumed for many years before $[8,16-20]$. It was shown that secreted, immune-modulating, nano-sized extracellular vesicles (EVs) mediate these paracrine effects. Preclinical data and first clinical data indicate that EVs, especially those derived from mesenchymal stem cells (MSCs), show great potential as therapeutic active agents in tissue regeneration and immune response modulation [21-25]. This is exemplified by an individual treatment attempt of an otherwise treatment resistant acute GvHD patient, who was treated over a 2-week period with escalating doses of an MSC-EV product. During the therapy, the aGvHD symptoms declined significantly, and the patient was stable for more than 4 months [26].

Here, we explored the potential of MSC-EVs, which were manufactured identically to those that were applied to the GvHD patient, in suppressing NPC associated symptomatology. We show that the intravenous administration of MSC-EVs into a mouse model for NPC1, namely Balb/cNctr-Npc1m1N/J mice, is able to reverse typical neurologic and systemic symptoms. More precisely, the MSC-EV treatment is able to lower inflammation in different brain regions and lower microgliosis and astrogliosis. Moreover, also a reduction in peripheral inflammation and number of foamy cells in the spleen, liver and lungs was observed upon MSC-EV treatment.

Taken together, this study demonstrates the potential of MSC-EVs in suppressing symptoms of the genetic neurovisceral lipid storage disease NPC. Administered MSC-EVs counteract both central and peripheral disease symptoms. 


\section{Results}

\subsection{MSC-EV Treatment Strategy of $\mathrm{NPC1}^{+/+}$and $\mathrm{NPC1}^{-/-}$Mice}

Here, we compared the therapeutic potential of two different MSC-EV preparations on NPC disease symptoms in NPC1 ${ }^{-/}$mice that carry a spontaneous loss of function mutation within the $\mathrm{Npc1}$ gene (deletion of 11 out of its 13 transmembrane domains) [27-29]. Both MSC-EV preparations were produced according to a standardized procedure, i.e., MSCs were expanded in non-EV depleted human platelet lysate supplemented media wit-h media changing intervals of $48 \mathrm{~h}$. EVs from conditioned media were prepared according to an optimized polyethylenglycol-based (PEG) precipitation method including a final ultracentrifugation polishing step [30,31]. Although both obtained MSC-EV preparations (MSC16.3-EV and MSC41.5-EV) revealed comparable EV characteristics, we previously reported that they exert different activities in an ischemic stroke as well as an optimized murine graft-versus.-host disease (GvHD) model and differed in their ability to modulate allogenic immune responses in vitro. Indeed, while the MSC41.5-EV preparation showed immunomodulatory activities in both animal models and in vitro, MSC16.3-EV failed to show therapeutic efficacy [32,33]. To compare their impact on typical systemic and neurologic features of the early-onset NPC1 pathology, aliquots of both MSC-EV preparations and of an EV preparation obtained from fresh, human platelet lysate supplemented MSC cultivation media (PL EV) were repetitively administered to $\mathrm{NPC1}^{-1-}$ mice. As displayed in Figure 1A, the treatment regime consisted of four intravenous injections between five and seven weeks of age. As negative control, mice were treated with the EV vehicle. At seven weeks of age, the effect of the treatment on both systemic and neurologic symptoms typical for NPC1 pathology was evaluated.

\subsection{MSC41.5-EV but Not MSC16.3-EV Treatment Protects against NPC1 ${ }^{-1-}$-Associated Weight Loss and Spleen Enlargement}

Similar to infants with NPC1 disorder, also NPC1 $1^{-/-}$mice show a progressive lower weight compared to their wildtype littermates (Figure S1) [2]. To evaluate if this phenotype can be reversed by MSC-EV treatment, we followed up the weight of the treated and control mice over the treatment period and plotted their weight gain in comparison to the weight at the start of the treatment. All treatment groups except the MSC41.5-EV treated mice revealed a comparable weight gain over the treatment time. Indeed, $\mathrm{NPC1}^{-/-}$mice that received MSC41.5-EVs gained, however not significantly, more weight over time compared with that of all other treatment groups (Figure 1B).

Next, we evaluated the effect on splenomegaly, another typical characteristic of NPC1 pathology (Figure 1C). MSC41.5-EVs, but not MSC16.3-EVs, were able to reduce the typical enlargement of the spleen observed in $\mathrm{NPC1}^{-/-}$mice treated with vehicle or PL EVs. Thus, our data indicate that MSC-EV preparations with therapeutic features provide the potential to effectively suppress NPC symptoms. As before, however, we observed that despite comparable EV characteristics, not all MSC-EV preparations obtain the required activity.

\subsection{MSC41.5-EV but Not MSC16.3-EV Treatment Reduces Peripheral Inflammation in $\mathrm{NPC1}^{-1-}$ Mice}

As there is multiple evidence that tumor necrosis factor (TNF) plays a key role in the pathogenesis of NPC1 in peripheral organs [34-41], we investigated whether MSC41.5-EV treatment decreases the expression of this pro-inflammatory cytokine (Figure 2A). At the gene expression level, we observed that $T n f$ expression is significantly increased in the liver and showed an increased trend in the lungs of $\mathrm{NPC}^{-/-}$mice compared to that of wild type $\mathrm{NPC}^{+/+}$littermates. Following MSC41.5-EV treatment, but not after administration of MSC16.3-EVs or PL-EVs, Tnf expression is significantly suppressed to normal, wild type levels in the liver. The same trend can be observed in the lungs. In spleen, no Tnf upregulation nor suppression could be observed due to NPC1 deficiency and MSC-EV treatment, respectively. 
A
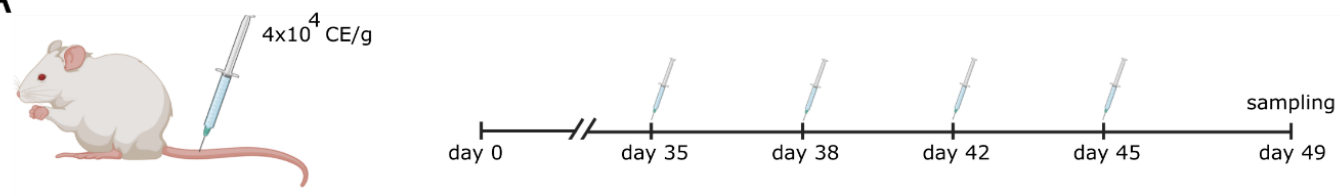

B
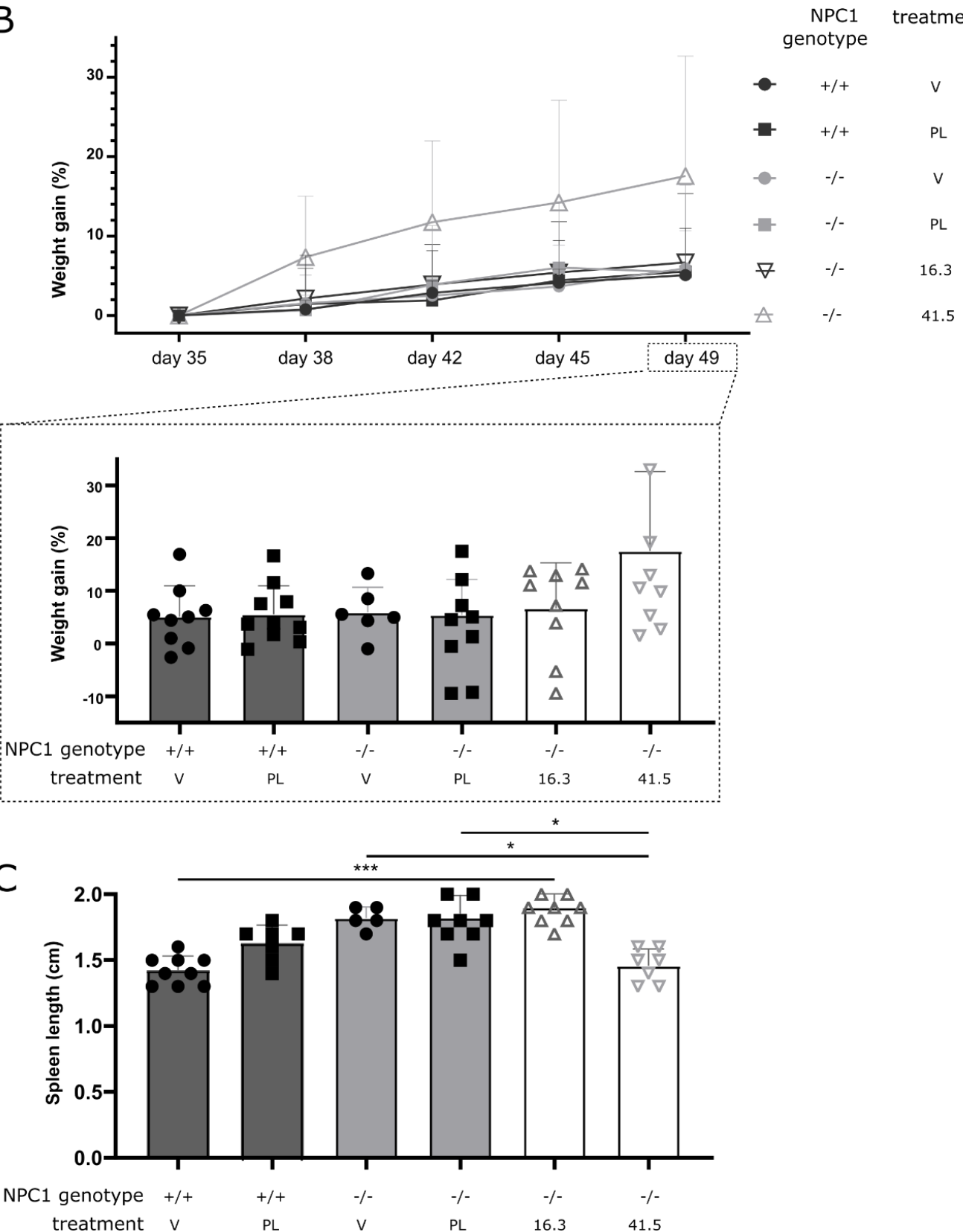

Figure 1. MSC41.5-EV administration restores overall weight gain and spleen size in $\mathrm{NPC} 1^{-/-}$mice. (A) NPC1 ${ }^{-/-}$mice and wild type littermates received $4 \times 10^{4}$ cell equivalents/gram (CE/g) EVs by intravenous injection into lateral tail vein. EVs were diluted in $10 \mathrm{mM}$ HEPES containing $0.9 \% \mathrm{NaCl}$ buffer. Control mice were injected with vehicle (buffer only). Three different EV preparations were tested: platelet lysate-derived EVs (PL), MSC16.3-EVs (16.3) and MSC41.5-EVs (41.5) harvested from conditioned media of MSCs expanded from donor stocks MSC16.3 or MSC41.5, respectively. (B,C) At age of 7 weeks, weight gain (B) compared to start of treatment and area of spleen (C) were calculated. Data are shown as mean \pm SEM ( $n=7$ to 9 mice per group). Statistical analyses on datasets were performed by Kruskal-Wallis test. Asterisks indicate statistical significance $\left({ }^{*} p<0.05,{ }^{* * *} p<0.001\right)$. V: vehicle; PL: platelet derived EVs; 16.3: MSC16.3-EVs; 41.5: MSC41.5-EVs. 
A
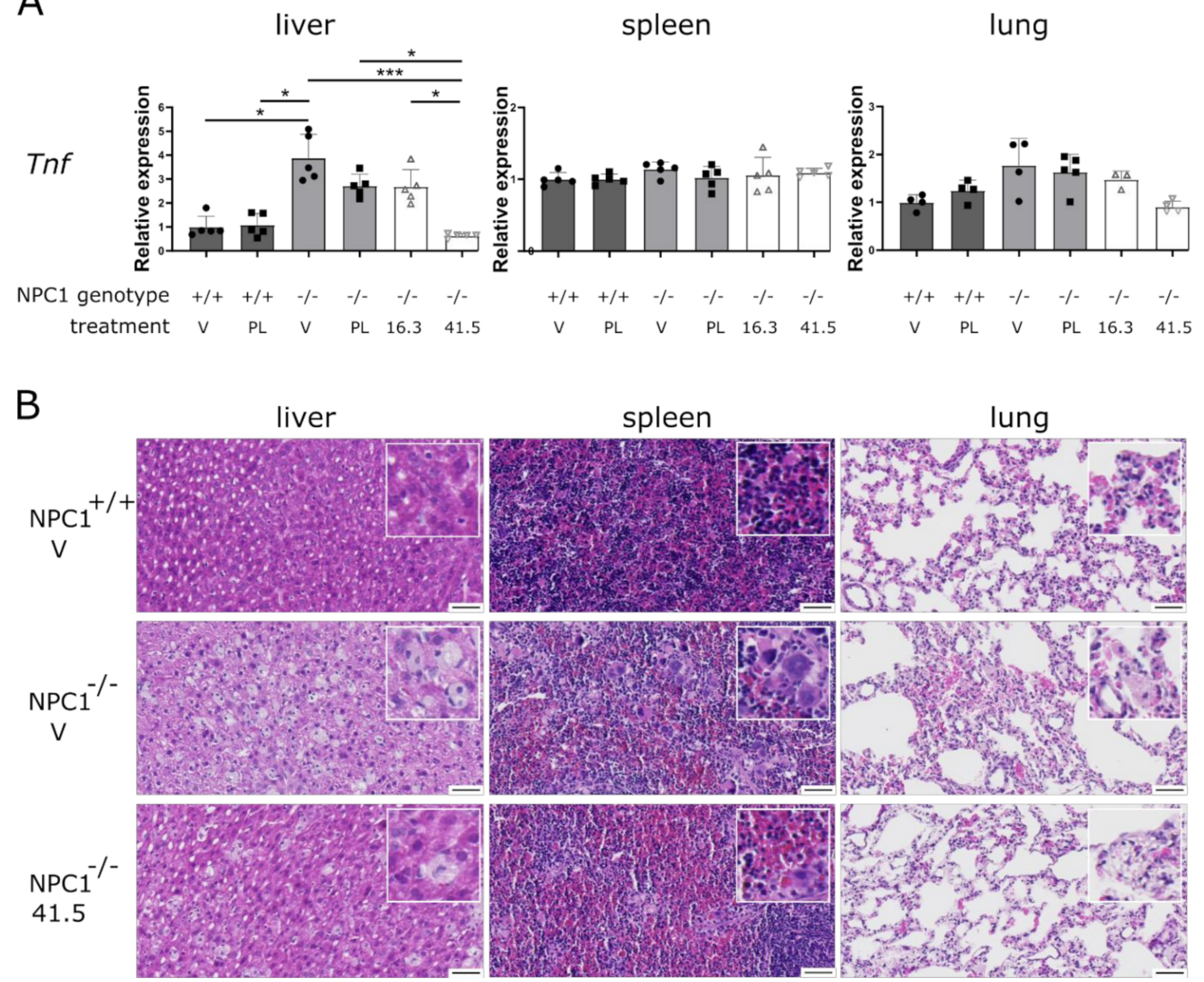

Figure 2. MSC41.5-EV treatment reduces $\mathrm{NPC} 1^{-/-}$pathology in peripheral organs. (A,B) $\mathrm{NPC} 1^{-/-}$mice and $\mathrm{NPC} 1^{+/+}$ littermates are treated four times by intravenous injection into lateral tail vein with vehicle (V), platelet derived EVs (PL), EVs harvested from donor MSC16.3 (16.3) or donor MSC41.5 (41.5) conditioned media. At age of 7 weeks, liver, spleen, and lungs were isolated followed by Tnf expression analysis (A) and hematoxylin and eosin (H \& E) staining (B). qRT-PCR results are represented relative to $\mathrm{NPC}^{+/+}$vehicle condition. Data are shown as mean $\pm \operatorname{SEM}(n=5$ mice per group). Statistical analyses on datasets were performed by Kruskal-Wallis test. Asterisks indicate statistical significance $\left({ }^{*} p<0.05\right.$, *** $p<0.001)$. Scale bars represent $50 \mu \mathrm{m}$.

To determine how MSC-EV treatment affects liver, spleen, and lung histology, H \& E stained-tissue sections were examined. $\mathrm{NPC}^{-/-}$mice extensively accumulate cytoplasmic lipids, resulting in foam cell formation [42]. Such foam cells are also formed in the liver, spleen, and lung of our $\mathrm{NPC}^{-/-}$mice, but not in their $\mathrm{NPC}^{+/+}$littermates (Figure 2B). In contrast, we hardly detected foam cells in NPC1 ${ }^{-/-}$mice that were treated with MSC41.5EVs. Neither treatment with PL- or MSC16.3-EVs was able to reduce the number of foam cells in spleen, liver, and lungs of NPC1 ${ }^{-/-}$mice (Figure S2).

Taken together, treatment of NPC1 pathology with EVs derived from conditioned media of the donor stock MSC41.5 but not MSC16.3 is able to reduce typical peripheral NPC1 symptoms.

\subsection{MSC41.5-EV Treatment Reduces Inflammation in Different Brain Regions in NPC1 ${ }^{-1-}$ Mice}

In addition to the spectrum of visceral symptoms, NPC1 pathology also impacts the central nervous system (CNS) and leads to neuroinflammation and -degeneration [43]. Here, we explored the expression strength of several cytokines and chemokines in different brain regions (Figure 3). As expected, compared to their healthy littermates, a significant increase in the expression of almost all tested inflammatory genes was found in $\mathrm{NPC}^{-/-}$ 
mice. Strikingly, administration of MSC41.5-EVs reduced this expression to almost normal levels and this holds true for all investigated brain regions, namely cerebellum, olfactory bulb, prefrontal cortex, and hippocampus. These results indicate that treatment with MSC41.5-EVs is able to suppress neuroinflammation in $\mathrm{NPC}^{-/-}$back to normal wild type level. In contrast, again neither treatment with PL EVs nor MSC16.3-EVs were able to reduce neuroinflammation (Figure S3).
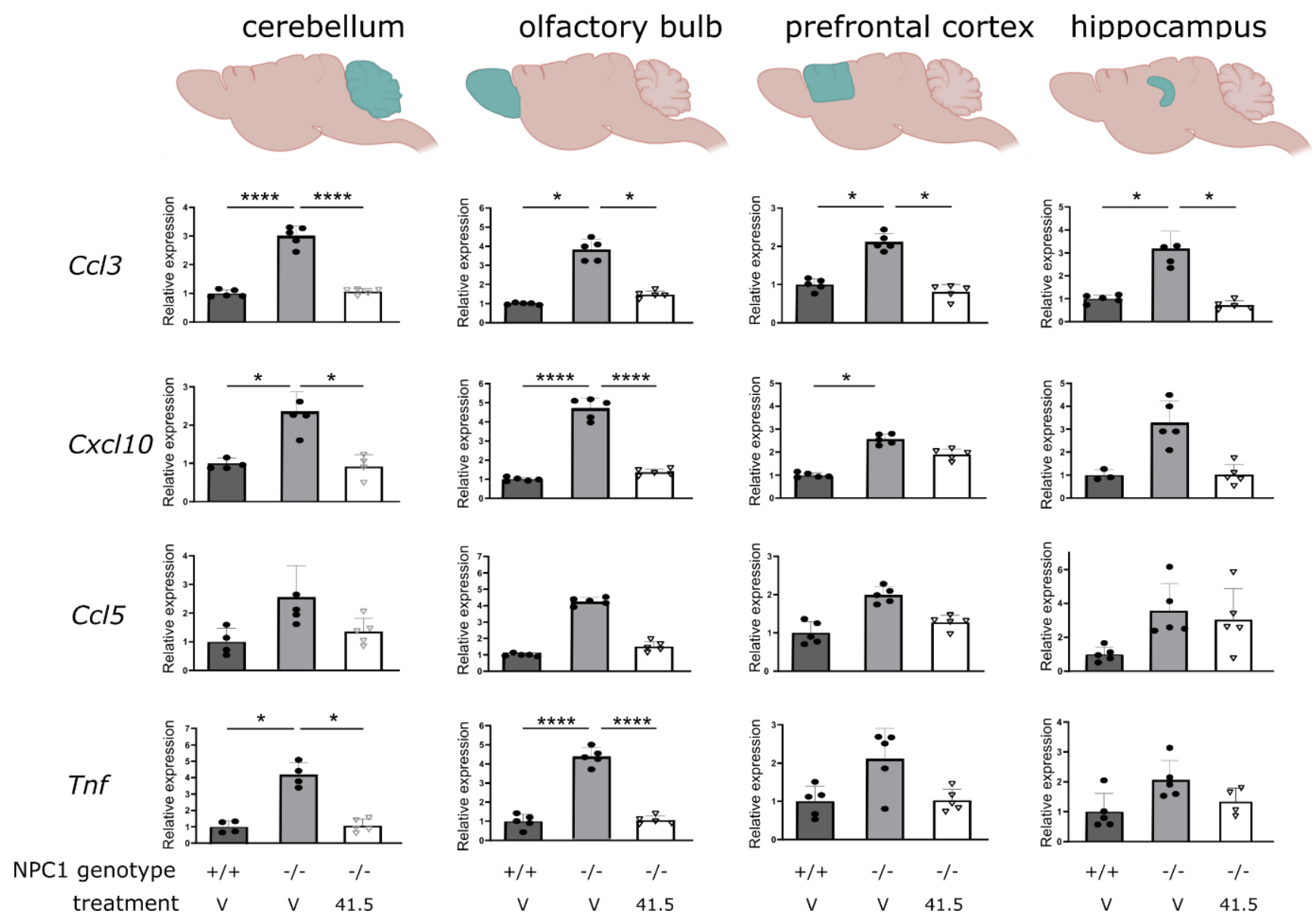

Figure 3. MSC41.5-EV treatment of $\mathrm{NPC} 1^{-/-}$mice reduces neuroinflammation in different brain regions. $\mathrm{NPC} 1^{-/-}$mice and wild type littermates are four times injected intravenous into lateral tail vein with vehicle or MSC-EVs derived from human MSC donor 41.2 (MSC-EV 41.2). At age of 7 weeks, different brain regions were isolated and Ccl3, Cxcl10, Ccl5 and Tnf gene expression was analyzed. Results are represented relative to $\mathrm{NPC1}^{+/+}$vehicle condition. Data are shown as mean \pm SEM ( $n=5$ mice per group). Statistical analyses on datasets were performed by Kruskal-Wallis test. Asterisks indicate statistical significance $\left({ }^{*} p<0.05,{ }^{* * * *} p<0.0001\right)$.

\subsection{MSC-EV Treatment Mitigates Microgliosis and Astrogliosis in $\mathrm{NPC1}^{-1-}$ Mice}

Astrocytosis and microgliosis are typical features of NPC1 pathology [6,43,44]. Analysis of astrocyte and microglia numbers in the hippocampus of $\mathrm{NPC}^{-/}$mice via IBA1 and GFAP stainings, respectively, revealed astrocytosis and microgliosis due to NPC1 deficiency (Figure 4). Again, this phenotype could almost completely be mitigated by the administration of MSC41.5-EVs in NPC1 $1^{-/-}$mice. 

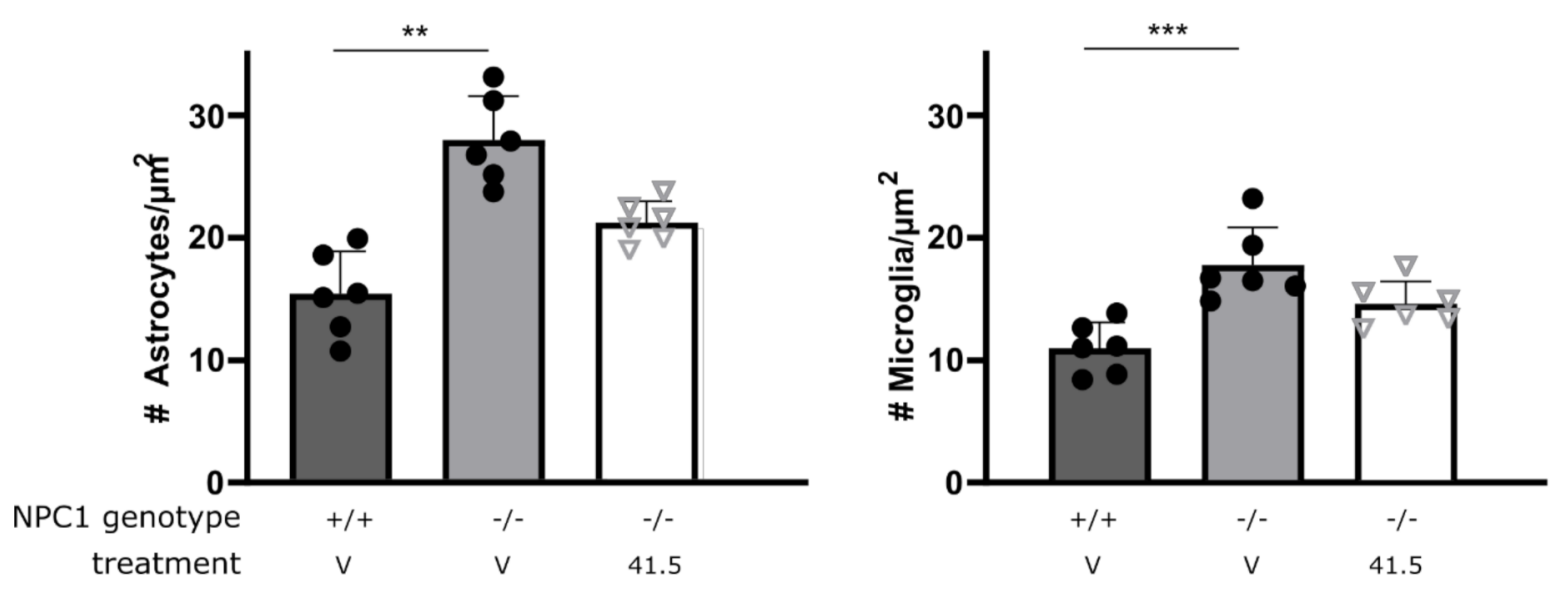

Figure 4. MSC41.5-EV treatment of $\mathrm{NPC}^{-/-}$mice reduces inflammation in different brain regions. $\mathrm{NPC} 1^{-/-}$mice and wild type littermates are treated four times by intravenous injection into lateral tail. At age of 7 weeks, brain was isolated and IBA and GFAP staining was performed on hippocampus. Data are shown as mean \pm SEM ( $n=6$ mice per group). Statistical analyses on datasets were performed by Kruskal-Wallis test. Asterisks indicate statistical significance $\left({ }^{* *} p<0.01\right.$, *** $p>0.001)$.

\section{Discussion}

Niemann-Pick disease type C1 (NPC1) is a rare progressive genetic disorder characterized by an inability of cells to transport cholesterol and lipids. This results in the abnormal accumulation of these substances within various tissues of the body, leading to a broad spectrum of visceral and neurological symptoms. Up to now, only symptomatic medication is available that alters specific NPC1-associated symptoms while no cure exists. As different studies show the immunomodulatory effect of EVs harvested from cell culture supernatants of humans MSCs [21,26,45-47], we here intravenously administered MSC-EVs harvested from different healthy human MSC donors (sources 16.3 and 41.5) in a mouse model for NPC1 pathology ( $\mathrm{NPC1}^{-/-}$) to investigate the modulatory effects on typical NPC1 disease features.

Infants with NPC1 usually develop splenomegaly by the age of 3 months and fail to gain weight and grow at the expected rate. Next to this, the inflammatory cytokine tumor necrosis factor (TNF) was suggested as an important cytokine in NPC1 disease progression as multiple members of the TNF pathway are overexpressed in peripheral organs of $\mathrm{NPC}^{-/-}$mice $[40,41,48]$. This pro-inflammatory cytokine plays an important role in apoptosis, inflammation and fibrosis, typical features of NPC1 diseased peripheral organs [36,38]. For example, it is shown that in the liver TNF that is secreted by foamy macrophages attract inflammatory cells and stimulate hepatic stellate cells, which deposit collagen and signals apoptosis of hepatocytes [34,35,37,39]. Moreover, Rimkunas et al. showed that by utilizing NPC1-specific antisense oligonucleotides to knock down NPC1 expression in control and TNF knockout mice, in the absence of TNF inflammation, apoptosis and fibrosis were present [40].

Here, we show that treatment with EVs isolated from MSCs of donor 41.5 is able to alter the above-described typical visceral features of NPC1 pathology. More precisely, we observed that treatment of NPC1 deficient mice with MSC-EV type 41.5 improves weight gain and reduces spleen enlargement. The treatment also reverses the increased expression of the inflammatory cytokine Tnf in the liver and the lungs and remarkably decreases the amount of foam cells in the liver, spleen, and lungs.

Next to the pronounced effects on the peripheral pathology, also a clear improvement of the neurological symptoms was observed after treatment of $\mathrm{NPC1}^{-/-}$mice with MSCEV 41.5. Indeed, neuroinflammation, determined via gene expression analysis of $\mathrm{Ccl}$, $\mathrm{Ccl}$, Cxcl10, and Tnf, was almost completely reversed upon treatment with MSC41.5-EVs in all brain regions tested. Even more striking is the observation that MSC-EV 41.5 is able to 
reduce the level of astrogliosis and microgliosis, two prominent neuropathological features of the NPC1 disease. A possible explanation, however speculative, for the weight gain in $\mathrm{NPC}^{-/-}$mice upon treatment with MSC-EV type 41.5 is that a reduced severity of the peripheral and neurological symptoms, e.g., systemic inflammation and neuroinflammation results in less overall sickness behavior, which in turn leads to an increased/better appetite with the NPC1 diseased mice.

All these findings underline the therapeutic potential of EVs derived from MSC as treatment strategy for the genetic neurovisceral lipid storage disease NPC. Moreover, an EV-based therapy has various advantages over cell therapies as they are not self-replicating and as they can hardly sense environmental conditions, their biological activity can be predicted more precisely than that of cells [23]. However, important to keep in mind is that huge differences among independent MSC-EV preparations are reported, e.g., in cytokine profiles $[11,26]$. Recently, Madel et al. showed therapeutic differences among independent MSC-EV preparations that had been produced in a standardized manner [32]. Also in our study, we show that the effects observed upon treatment with MSV-EV type 41.5 are in shear contrast to the results obtained upon treatment with EVs isolated from MSC of donor 16.3. Indeed, despite treatment with similar particle numbers of EVs isolated from donor 16.3 MSCs compared to 41.5, the investigated features were not reduced and were comparable to $\mathrm{NPC}^{-/-}$mice treated with vehicle or platelet derived EVs. These results are in agreement with the in vitro immunomodulatory capacity of both MSC-EV fractions [32,33]. Consequently, functional testing of any MSC-EV preparation is necessary prior to clinical application. Unfortunately, it is currently nondeducible from the MSCs phenotypes whether resulting EV preparations have a higher or lower chance to be therapeutically active. So, before MSC-EV treatment strategies can be used to treat NPC1 patients, reliable methodologies need to be developed to determine the in vivo immunomodulatory potential of a specific MSV-EV batch.

Taken together, MSC-EV administration modulates NPC1 pathology in mice on the level of visceral as well as neurologic symptoms. These results may open new treatment perspectives for the so far hard to treat disease NPC1.

\section{Materials and Methods}

\subsection{Mice}

Balb/cNctr-Npc1 $1^{m 1 N} / \mathrm{J}$ mice aged five to seven weeks were used. These mice harbor an insertion in chromosome 18, resulting in a premature truncation of the NPC1 protein deleting 11 out of 13 transmembrane domains. In all experiments, mice were age- and gender-matched with wild type littermates. All mice were housed with 14 to $10 \mathrm{~h}$ light and dark cycles and free access to food and water in SPF conditions. All experiments comply with the current laws of Belgium and were approved by the animal ethics committee of Ghent University (EC 2015-052; 29/10/2015).

\subsection{Preparation of EVs}

MSCs were raised from bone marrow samples of two healthy human donors exactly as described previously [26,49]. For the EV harvesting, MSCs from two different MSC stocks, MSC16.3 and MSC41.5, were expanded at $37{ }^{\circ} \mathrm{C}$ in a $5 \% \mathrm{CO}_{2}$ atmosphere in DMEM low glucose basal media (PAN Biotech, Aidenbach, Germany), supplemented with $10 \%$ human platelet lysate, $100 \mathrm{U} / \mathrm{mL}$ penicillin-streptomycin-glutamine (Thermo Fisher Scientific, Darmstadt, Germany) and $5 \mathrm{IU} / \mathrm{mL}$ Heparin (Ratiopharm, Ulm, Germany) exactly as described previously [26]. Starting at $\sim 50-80 \%$ confluency, media exchanges were performed every $48 \mathrm{~h}$. For the cryopreservation at $-20{ }^{\circ} \mathrm{C}$, larger debris were removed from the conditioned media by $2000 \times g$ centrifugation for 15 min (Rotor: JS5.3; Beckman Coulter, Brea, CA, USA). After thawing, MSC-EVs as well as platelet EVs from non-conditioned, fresh MSC-media were prepared using an optimized polyethylene glycole 6000 precipitation protocol followed by ultracentrifugation exactly as reported previously [26,31]. The EV harvest of conditioned media of $4 \times 10^{7}$ MSCs were solved in 1 
mL 10 mM HEPES (Gibco, Waltham, MA, USA) 0.9\% NaCl (bBraun, Bucharest, Romania) buffer and stored at $-80^{\circ} \mathrm{C}$ until usage. Both MSC-EV and the PL EV preparation were characterized according to the minimal information for studies of extracellular vesicles 2018 (MISEV2018) guidelines [50]. The same MSC-EVs are used as by Wang et al. and Madel et al. [32,33]. Full characterization of the MSC-EV fractions was reported previously in [33]. Table 1 gives an overview of the protein concentration and size of the used EVs (Table 1).

Table 1. Overview of protein concentration and size (NTA-determined) of used EVs.

\begin{tabular}{ccc}
\hline EV Type & Protein Concentration $(\mu \mathrm{g} / \mu \mathrm{L})$ & Size $(\mathrm{nm})$ \\
\hline MSC41.5-EVs & 4.80 & 125.6 \\
MSC16.3-EVs & 4.89 & 114.5 \\
PL EV & 7.52 & 125.2 \\
\hline
\end{tabular}

\subsection{Treatment}

The mice were intravenously injected with $4 \times 10^{4}$ cell equivalents (CE) EVs/g diluted in $10 \mathrm{mM}$ HEPES in $0.9 \% \mathrm{NaCl}$ buffer or with vehicle only as negative control. The treatment was administered four times over a period of two weeks, starting when the mice were 5 weeks of age. At the age of 7 weeks, the mice were sacrificed (Figure 1A). The study was performed blinded, meaning that the activity of the MSC-EV preparations was unknown for the researchers performing the injections and evaluating the effect of the treatment on NPC1 pathology.

\subsection{Tissue Isolation}

For RNA or protein analysis, mice were transcardially perfused with a D-PBS/heparin (0.2\% heparin (5000 IU / mL, Wockhardt, Mumbai, India)) supplemented with 0.5\% bromophenol blue (Sigma, St. Louis, MO, USA). Spleen, liver, lung, hippocampus, cerebellum, olfactory bulb, prefrontal cortex was dissected out and snap-frozen in liquid nitrogen. For immunohistochemical analysis, mice were transcardially perfused with 4\% PFA, and spleen, liver, lung, and brain samples were isolated, fixed in $4 \%$ PFA and processed for paraffin-embedding.

\subsection{RNA Isolation and Real-Time qPCR}

RNA was isolated from all tissues using the Aurum total RNA Mini Kit (Bio-Rad), according to the manufacturer's instructions. RNA concentration and purity were determined spectrophotometrically using the Nanodrop ND-1000 (Nanodrop Technologies, Thermo Scientific, Bucharest, Romania) and cDNA was synthesized with the SensiFAST ${ }^{\mathrm{TM}}$ cDNA Synthesis Kit (Bioline, London, UK). RT-qPCR was performed with the Light Cycler 480 system (Roche, Basel, Switzerland) using SensiFast SYBR No-Rox (Bio-Line). Expression levels were normalized to the expression of two or three most stable reference genes, determined using the geNorm Housekeeping Gene Selection Software. The sequences of the forward and reversed primers for the different genes are provided (Table 2).

\subsection{Immunohistochemistry}

For immunostaining on mouse brain sections, $5 \mu \mathrm{m}$ sections were prepared from paraffin-embedded samples. Sections were dewaxed using Varistain (Thermo Fisher Scientific), followed by an antigen retrieval step using citrate buffer (Vector; H-3300) and wash steps with PBS-T (PBS supplemented with 0.5\% Triton X-100). Next, endogenous peroxidase activity was blocked with $3 \% \mathrm{H}_{2} \mathrm{O}_{2}$ in methanol for $10 \mathrm{~min}$. Samples were blocked with bovine serum albumin (BSA) and 5\% normal goat serum in PBS-T $(0.5 \%(w / v)$ BSA and $0.02 \%(v / v)$ Triton X-100 in PBS) for $30 \mathrm{~min}$ at RT, followed by overnight incubation at $4{ }^{\circ} \mathrm{C}$ with primary antibody against GFAP (1:1000; Agilent; Z033429-2) or IBA1 (1:200; Wako Chemicals, 019-19741). After ON incubation, slides were washed with PBS-T and incubated with goat anti-rabbit biotinylated antibody (1:500; Dako, E0432). Visualization 
was done using ABC (Vector; PK6100) and DAB. Next, slides were counterstained with hematoxylin, dehydrated to xylene and mounted with Entellan. Image acquisition was performed using a slide scanner (Zeiss, Axio Scan) and analyzed using the Zen software (Carl Zeiss Microscopy GmbH, Jena, Germany, 2012).

Table 2. Overview of used RT-qPCR primer sequences.

\begin{tabular}{|c|c|c|}
\hline Gene & Forward & Reverse \\
\hline Gapdh & TGAAGCAGGCATCTGAGGG & CGAAGGTGGAAGAGTGGGAG \\
\hline Hprt & AGTGTTGGATACAGGCCAGAC & CGTGATTCAAATCCCTGAAGT \\
\hline$R p l$ & CCTGCTGCTCTCAAGGTT & TGGTTGTCACTGCCTCGTACTT \\
\hline$U b c$ & AGGTCAAACAGGAAGACAGACGTA & TCACACCCAAGAACAAGCACA \\
\hline Ccl3 & TTCTCTGTACCATGACACTCTGC & CGTGGAATCTTCCGGCTGTAG \\
\hline Ccl5 & GCTGCTTTGCCTACCTCTCC & TCGAGTGACAAACACGACTGC \\
\hline Cxcl10 & CCAAGTGCTGCCGTCATTTTC & GGCTCGCAGGGATGATTTCAA \\
\hline Tnf & ACCCTGGTATGAGCCCATATAC & ACACCCATTCCCTTCACAGAG \\
\hline
\end{tabular}

\section{Statistical Analysis}

Statistical analyses were performed using GraphPad Prism 9.0 (GraphPad Software, Inc. San Diego, CA, USA). Bars represent mean \pm SEM. qPCR data were analyzed with an unpaired $t$-test unless mentioned differently. Significance levels are indicated ${ }^{*} 0.01 \leq p<0.05 ;{ }^{* *} 0.001 \leq p<0.01 ;{ }^{* *} 0.001 \leq p<0.0001$; and ${ }^{* * * *} p<0.0001$.

Supplementary Materials: The following are available online at https: / www.mdpi.com/article / 10.3390/biomedicines9121864/s1, Figure S1: NPC1 ${ }^{-/-}$mice show a progressive lower weight compared to their wildtype littermates, Figure S2: MSC-EV type 16.3 has no effect on NPC1 ${ }^{-/-}$ pathology in peripheral organs, Figure S3: MSC-EV 16.3 treatment of $\mathrm{NPC1}^{-/}$- mice has no effect on inflammation in different brain regions

Author Contributions: L.V.H., C.V.C., A.B., B.G. and R.E.V. designed experiments; L.V.H., C.V.C., J.C., G.V.I., E.V.W., V.B., R.D., W.C., J.X. performed experiments; L.V.H. and R.E.V. wrote the manuscript. All authors reviewed the manuscript before submission. All authors have read and agreed to the published version of the manuscript.

Funding: This work was supported by the Belgian Foundation of Alzheimer's Research (SAO; project number: 20200032), the Research Foundation Flanders (FWO Vlaanderen; project numbers: $11 \mathrm{~A} 6420 \mathrm{~N}$ and $1547420 \mathrm{~N}$ ) and the Baillet Latour Fund. This study was supported by the LeitmarktAgentur.NRW and the European Union (European Regional Development Fund 2014-2020, EFRE-0800396), the Stem Cell Network North Rhine Westphalia and the European Union (ERA-NET EuroTransbio 11: EVTrust [031B0332B]; EU COST program ME-HaD [BM1202]) as well as by the "Niemann-Pick Selbsthilfegruppe e. V." and "Bild hilft" (PÄ 36008).

Institutional Review Board Statement: The study was conducted according to the guidelines of the Declaration of Helsinki, and approved by the Institutional Ethics Committee of Ghent University (EC 2015-052; 29 October 2015).

Informed Consent Statement: Not applicable.

Data Availability Statement: The original contributors presented in the study are included in the article/supplementary Material, further inquiries can be directed to the corresponding author.

Acknowledgments: We thank the VIB BioImaging Core for training, support and access to the instrument park.

Conflicts of Interest: Bernd Giebel is a scientific advisory board member of Innovex Therapeutics SL and Mursla Ltd. and a founding director of Exosla Ltd. All other authors report no conflicts of interest. 


\section{References}

1. Vanier, M.T. Complex lipid trafficking in Niemann-Pick disease type C. J. Inherit. Metab. Dis. 2015, 38, 187-199. [CrossRef] [PubMed]

2. Lamri, A.; Pigeyre, M.; Garver, W.S.; Meyre, D. The Extending Spectrum of NPC1-Related Human Disorders: From Niemann-Pick C1 Disease to Obesity. Endocr. Rev. 2018, 39, 192-220. [CrossRef] [PubMed]

3. Mengel, E.; Klunemann, H.H.; Lourenco, C.M.; Hendriksz, C.J.; Sedel, F.; Walterfang, M.; Kolb, S.A. Niemann-Pick disease type C symptomatology: An expert-based clinical description. Orphanet J. Rare Dis. 2013, 8, 166. [CrossRef] [PubMed]

4. Rodriguez-Gil, J.L.; Watkins-Chow, D.E.; Baxter, L.L.; Yokoyama, T.; Zerfas, P.M.; Starost, M.F.; Gahl, W.A.; Malicdan, M.C.V.; Porter, F.D.; Platt, F.M.; et al. NPC1 Deficiency in Mice is Associated with Fetal Growth Restriction, Neonatal Lethality and Abnormal Lung Pathology. J. Clin. Med. 2019, 9, 12. [CrossRef]

5. Walterfang, M.; Di Biase, M.A.; Cropley, V.L.; Scott, A.M.; O’Keefe, G.; Velakoulis, D.; Pathmaraj, K.; Ackermann, U.; Pantelis, C. Imaging of neuroinflammation in adult Niemann-Pick type C disease: A cross-sectional study. Neurology 2020, 94, e1716-e1725. [CrossRef] [PubMed]

6. Platt, N.; Speak, A.O.; Colaco, A.; Gray, J.; Smith, D.A.; Williams, I.M.; Wallom, K.L.; Platt, F.M. Immune dysfunction in Niemann-Pick disease type C. J. Neurochem. 2016, 136 (Suppl. S1), 74-80. [CrossRef]

7. Vanier, M.T. Niemann-Pick disease type C. Orphanet J. Rare Dis. 2010, 5, 16. [CrossRef]

8. Lee, R.H.; Pulin, A.A.; Seo, M.J.; Kota, D.J.; Ylostalo, J.; Larson, B.L.; Semprun-Prieto, L.; Delafontaine, P.; Prockop, D.J. Intravenous hMSCs improve myocardial infarction in mice because cells embolized in lung are activated to secrete the anti-inflammatory protein TSG-6. Cell Stem Cell 2009, 5, 54-63. [CrossRef] [PubMed]

9. Bartholomew, A.; Sturgeon, C.; Siatskas, M.; Ferrer, K.; McIntosh, K.; Patil, S.; Hardy, W.; Devine, S.; Ucker, D.; Deans, R.; et al. Mesenchymal stem cells suppress lymphocyte proliferation in vitro and prolong skin graft survival in vivo. Exp. Hematol. 2002, 30, 42-48. [CrossRef]

10. Di Nicola, M.; Carlo-Stella, C.; Magni, M.; Milanesi, M.; Longoni, P.D.; Matteucci, P.; Grisanti, S.; Gianni, A.M. Human bone marrow stromal cells suppress T-lymphocyte proliferation induced by cellular or nonspecific mitogenic stimuli. Blood 2002, 99, 3838-3843. [CrossRef] [PubMed]

11. Le Blanc, K.; Rasmusson, I.; Sundberg, B.; Gotherstrom, C.; Hassan, M.; Uzunel, M.; Ringden, O. Treatment of severe acute graft-versus-host disease with third party haploidentical mesenchymal stem cells. Lancet 2004, 363, 1439-1441. [CrossRef]

12. Galipeau, J. The mesenchymal stromal cells dilemma-Does a negative phase III trial of random donor mesenchymal stromal cells in steroid-resistant graft-versus-host disease represent a death knell or a bump in the road? Cytotherapy 2013, 15, 2-8. [CrossRef]

13. Kebriaei, P.; Hayes, J.; Daly, A.; Uberti, J.; Marks, D.I.; Soiffer, R.; Waller, E.K.; Burke, E.; Skerrett, D.; Shpall, E.; et al. A Phase 3 Randomized Study of Remestemcel-L versus Placebo Added to Second-Line Therapy in Patients with Steroid-Refractory Acute Graft-versus-Host Disease. Biol. Blood Marrow Transpl. 2020, 26, 835-844. [CrossRef] [PubMed]

14. Kurtzberg, J.; Abdel-Azim, H.; Carpenter, P.; Chaudhury, S.; Horn, B.; Mahadeo, K.; Nemecek, E.; Neudorf, S.; Prasad, V.; Prockop, S.; et al. A Phase 3, Single-Arm, Prospective Study of Remestemcel-L, Ex Vivo Culture-Expanded Adult Human Mesenchymal Stromal Cells for the Treatment of Pediatric Patients who Failed to Respond to Steroid Treatment for Acute Graft-versus-Host Disease. Biol. Blood Marrow Transpl. 2020, 26, 845-854. [CrossRef] [PubMed]

15. Kurtzberg, J.; Prockop, S.; Chaudhury, S.; Horn, B.; Nemecek, E.; Prasad, V.; Satwani, P.; Teira, P.; Hayes, J.; Burke, E.; et al. Study 275: Updated Expanded Access Program for Remestemcel-L in Steroid-Refractory Acute Graft-versus-Host Disease in Children. Biol. Blood Marrow Transpl. 2020, 26, 855-864. [CrossRef]

16. Gnecchi, M.; He, H.; Liang, O.D.; Melo, L.G.; Morello, F.; Mu, H.; Noiseux, N.; Zhang, L.; Pratt, R.E.; Ingwall, J.S.; et al. Paracrine action accounts for marked protection of ischemic heart by Akt-modified mesenchymal stem cells. Nat. Med. 2005, 11, 367-368. [CrossRef] [PubMed]

17. Gnecchi, M.; He, H.; Noiseux, N.; Liang, O.D.; Zhang, L.; Morello, F.; Mu, H.; Melo, L.G.; Pratt, R.E.; Ingwall, J.S.; et al. Evidence supporting paracrine hypothesis for Akt-modified mesenchymal stem cell-mediated cardiac protection and functional improvement. FASEB J. 2006, 20, 661-669. [CrossRef] [PubMed]

18. Lai, R.C.; Arslan, F.; Lee, M.M.; Sze, N.S.; Choo, A.; Chen, T.S.; Salto-Tellez, M.; Timmers, L.; Lee, C.N.; El Oakley, R.M.; et al. Exosome secreted by MSC reduces myocardial ischemia/reperfusion injury. Stem Cell Res. 2010, 4, 214-222. [CrossRef] [PubMed]

19. Zanotti, L.; Sarukhan, A.; Dander, E.; Castor, M.; Cibella, J.; Soldani, C.; Trovato, A.E.; Ploia, C.; Luca, G.; Calvitti, M.; et al. Encapsulated mesenchymal stem cells for in vivo immunomodulation. Leukemia 2013, 27, 500-503. [CrossRef]

20. Timmers, L.; Lim, S.K.; Arslan, F.; Armstrong, J.S.; Hoefer, I.E.; Doevendans, P.A.; Piek, J.J.; El Oakley, R.M.; Choo, A.; Lee, C.N.; et al. Reduction of myocardial infarct size by human mesenchymal stem cell conditioned medium. Stem Cell Res. 2007, 1, 129-137. [CrossRef]

21. Borger, V.; Bremer, M.; Ferrer-Tur, R.; Gockeln, L.; Stambouli, O.; Becic, A.; Giebel, B. Mesenchymal Stem/Stromal Cell-Derived Extracellular Vesicles and Their Potential as Novel Immunomodulatory Therapeutic Agents. Int. J. Mol. Sci. 2017, 18, 1450. [CrossRef] [PubMed]

22. Giebel, B.; Kordelas, L.; Borger, V. Clinical potential of mesenchymal stem/stromal cell-derived extracellular vesicles. Stem Cell Investig. 2017, 4, 84. [CrossRef] 
23. Lener, T.; Gimona, M.; Aigner, L.; Borger, V.; Buzas, E.; Camussi, G.; Chaput, N.; Chatterjee, D.; Court, F.A.; Del Portillo, H.A.; et al. Applying extracellular vesicles based therapeutics in clinical trials-An ISEV position paper. J. Extracell. Vesicles 2015, 4, 30087. [CrossRef] [PubMed]

24. Luo, T.; von der Ohe, J.; Hass, R. MSC-Derived Extracellular Vesicles in Tumors and Therapy. Cancers 2021, 13, 5212. [CrossRef] [PubMed]

25. Slomka, A.; Urban, S.K.; Lukacs-Kornek, V.; Zekanowska, E.; Kornek, M. Large Extracellular Vesicles: Have We Found the Holy Grail of Inflammation? Front. Immunol. 2018, 9, 2723. [CrossRef] [PubMed]

26. Kordelas, L.; Rebmann, V.; Ludwig, A.K.; Radtke, S.; Ruesing, J.; Doeppner, T.R.; Epple, M.; Horn, P.A.; Beelen, D.W.; Giebel, B. MSC-derived exosomes: A novel tool to treat therapy-refractory graft-versus-host disease. Leukemia 2014, 28, 970-973. [CrossRef] [PubMed]

27. Colombo, A.; Dinkel, L.; Muller, S.A.; Sebastian Monasor, L.; Schifferer, M.; Cantuti-Castelvetri, L.; Konig, J.; Vidatic, L.; BremovaErtl, T.; Lieberman, A.P.; et al. Loss of NPC1 enhances phagocytic uptake and impairs lipid trafficking in microglia. Nat. Commun. 2021, 12, 1158. [CrossRef] [PubMed]

28. Loftus, S.K.; Morris, J.A.; Carstea, E.D.; Gu, J.Z.; Cummings, C.; Brown, A.; Ellison, J.; Ohno, K.; Rosenfeld, M.A.; Tagle, D.A.; et al Murine model of Niemann-Pick C disease: Mutation in a cholesterol homeostasis gene. Science 1997, 277, 232-235. [CrossRef] [PubMed]

29. Pentchev, P.G.; Gal, A.E.; Booth, A.D.; Omodeo-Sale, F.; Fouks, J.; Neumeyer, B.A.; Quirk, J.M.; Dawson, G.; Brady, R.O. A lysosomal storage disorder in mice characterized by a dual deficiency of sphingomyelinase and glucocerebrosidase. Biochim. Biophys. Acta 1980, 619, 669-679. [CrossRef]

30. Borger, V.; Staubach, S.; Dittrich, R.; Stambouli, O.; Giebel, B. Scaled Isolation of Mesenchymal Stem/Stromal Cell-Derived Extracellular Vesicles. Curr. Protoc. Stem Cell Biol. 2020, 55, e128. [CrossRef] [PubMed]

31. Ludwig, A.K.; De Miroschedji, K.; Doeppner, T.R.; Borger, V.; Ruesing, J.; Rebmann, V.; Durst, S.; Jansen, S.; Bremer, M.; Behrmann, E.; et al. Precipitation with polyethylene glycol followed by washing and pelleting by ultracentrifugation enriches extracellular vesicles from tissue culture supernatants in small and large scales. J. Extracell. Vesicles 2018, 7, 1528109. [CrossRef] [PubMed]

32. Madel, R.J.; Borger, V.; Dittrich, R.; Bremer, M.; Tertel, T.; Ngo Thi Phuong, N.; Babo, H.A.; Kordelas, L.; Buer, J.; Horn, P.A.; et al. Independent human mesenchymal stromal cell-derived extracellular vesicle preparations differentially affect symptoms in an advanced murine Graft-versus-Host-Disease model. bioRxiv 2020. [CrossRef]

33. Wang, C.; Borger, V.; Sardari, M.; Murke, F.; Skuljec, J.; Pul, R.; Hagemann, N.; Dzyubenko, E.; Dittrich, R.; Gregorius, J.; et al. Mesenchymal Stromal Cell-Derived Small Extracellular Vesicles Induce Ischemic Neuroprotection by Modulating Leukocytes and Specifically Neutrophils. Stroke 2020, 51, 1825-1834. [CrossRef] [PubMed]

34. Bataller, R.; Brenner, D.A. Liver fibrosis. J. Clin. Investig. 2005, 115, 209-218. [CrossRef]

35. Bilzer, M.; Roggel, F.; Gerbes, A.L. Role of Kupffer cells in host defense and liver disease. Liver Int. 2006, 26, 1175-1186. [CrossRef]

36. Bradham, C.A.; Plumpe, J.; Manns, M.P.; Brenner, D.A.; Trautwein, C. Mechanisms of hepatic toxicity. I. TNF-induced liver injury. Am. J. Physiol. 1998, 275, G387-G392.

37. Copaci, I.; Micu, L.; Voiculescu, M. The role of cytokines in non-alcoholic steatohepatitis. A review. J. Gastrointest. Liver Dis. 2006, $15,363-373$.

38. Fausto, N.; Laird, A.D.; Webber, E.M. Liver regeneration. 2. Role of growth factors and cytokines in hepatic regeneration. FASEB J. 1995, 9, 1527-1536. [CrossRef] [PubMed]

39. Kolios, G.; Valatas, V.; Kouroumalis, E. Role of Kupffer cells in the pathogenesis of liver disease. World J. Gastroenterol. 2006, 12, 7413-7420. [CrossRef]

40. Rimkunas, V.M.; Graham, M.J.; Crooke, R.M.; Liscum, L. In vivo antisense oligonucleotide reduction of NPC1 expression as a novel mouse model for Niemann Pick type C- associated liver disease. Hepatology 2008, 47, 1504-1512. [CrossRef] [PubMed]

41. Wu, Y.P.; Mizukami, H.; Matsuda, J.; Saito, Y.; Proia, R.L.; Suzuki, K. Apoptosis accompanied by up-regulation of TNF-alpha death pathway genes in the brain of Niemann-Pick type C disease. Mol. Genet. Metab. 2005, 84, 9-17. [CrossRef] [PubMed]

42. Maxfield, F.R.; Tabas, I. Role of cholesterol and lipid organization in disease. Nature 2005, 438, 612-621. [CrossRef]

43. Cologna, S.M.; Cluzeau, C.V.; Yanjanin, N.M.; Blank, P.S.; Dail, M.K.; Siebel, S.; Toth, C.L.; Wassif, C.A.; Lieberman, A.P.; Porter, F.D. Human and mouse neuroinflammation markers in Niemann-Pick disease, type C1. J. Inherit. Metab. Dis. 2014, $37,83-92$. [CrossRef] [PubMed]

44. Baudry, M.; Yao, Y.; Simmons, D.; Liu, J.; Bi, X. Postnatal development of inflammation in a murine model of Niemann-Pick type C disease: Immunohistochemical observations of microglia and astroglia. Exp. Neurol. 2003, 184, 887-903. [CrossRef]

45. Giebel, B.; Hermann, D.M. Identification of the right cell sources for the production of therapeutically active extracellular vesicles in ischemic stroke. Ann. Transl. Med. 2019, 7, 188. [CrossRef]

46. Lai, P.; Weng, J.; Guo, L.; Chen, X.; Du, X. Novel insights into MSC-EVs therapy for immune diseases. Biomark. Res. 2019, 7, 6. [CrossRef] [PubMed]

47. Lv, L.L.; Wu, W.J.; Feng, Y.; Li, Z.L.; Tang, T.T.; Liu, B.C. Therapeutic application of extracellular vesicles in kidney disease: Promises and challenges. J. Cell. Mol. Med. 2018, 22, 728-737. [CrossRef] [PubMed]

48. Beltroy, E.P.; Richardson, J.A.; Horton, J.D.; Turley, S.D.; Dietschy, J.M. Cholesterol accumulation and liver cell death in mice with Niemann-Pick type C disease. Hepatology 2005, 42, 886-893. [CrossRef] [PubMed] 
49. Radtke, S.; Gorgens, A.; Liu, B.; Horn, P.A.; Giebel, B. Human mesenchymal and murine stromal cells support human lymphomyeloid progenitor expansion but not maintenance of multipotent haematopoietic stem and progenitor cells. Cell Cycle 2016, 15, 540-545. [CrossRef]

50. Thery, C.; Witwer, K.W.; Aikawa, E.; Alcaraz, M.J.; Anderson, J.D.; Andriantsitohaina, R.; Antoniou, A.; Arab, T.; Archer, F.; Atkin-Smith, G.K.; et al. Minimal information for studies of extracellular vesicles 2018 (MISEV2018): A position statement of the International Society for Extracellular Vesicles and update of the MISEV2014 guidelines. J. Extracell. Vesicles 2018, 7, 1535750. [CrossRef] [PubMed] 